\title{
Amphiphilic hybrids containing inorganic constituent: More than soap
}

\author{
Sebastian Polarz *, James Arthur Odendal, Stefanie Hermann, Alexander Klaiber \\ Department of Chemistry, University of Konstanz, 78457 Konstanz, Germany
}

\begin{abstract}
A B S T R A C T
Amphiphiles and surfactants are indispensable compounds in industry, scientific research and everyday life, such as emulsification agents, detergents, etc. The vast majority of currently used amiphiphiles are organic in nature, and are composed of two molecular parts joined together, one hydrophilic and one hydrophobic. The current article highlights some of the recent developments in the emerging field of hybrid amphiphiles, focusing on systems with at least one inorganic constituent. Different classes of amphiphiles can be defined, depending on if the inorganic entity is molecular or has particle character, and depending on the strength of interaction between the inorganic and organic phase. It is seen that in addition to typical amphiphilic properties, most importantly the formation of self assembled structures like micelles or lyotropic liquid crystals, the hybrid amphiphiles exhibit additional, functional features like special magnetic or catalytic properties. Ultimately, systemic features can be observed, leading to the emergence of new properties which none of the constituents of hybrid amphiphile could have on its own.
\end{abstract}

Keywords:

Self-assembly

Polyoxometalates

Organic-inorganic hybrids

Amphiphiles

Janus particles

\section{Introduction and background}

The persistent, general question in materials science is, how novel materials with unique and ultimately unprecedented properties can be found. A strategy, proven to be quite successful, is to combine seem ingly opposite entities, hoping for systemic features. A very superficial description of systemic features is that the whole is more than the sum of its parts, found for instance in swarms of certain ensembles e.g. particles [1]. A very obvious choice for joining opposites is to com bine organic and inorganic constituents, and this has resulted in the vast field of 'organic inorganic hybrids' with numerous examples of synergistic properties [ $\left.2^{\circ}\right]$. Another prominent case for a chemical an tagonism joined together in one system is represented by surfactants, the latter term representing an abbreviation for surface active agents.

Surfactants are defined as molecular compounds containing one water compatible, hydrophilic part, the so called head group, and a water incompatible, hydrophobic part covalently linked to each other. The hydrophobic unit of a classical surfactant is typically a simple alkyl chain, whereas the hydrophilic part can be cationic (e.g. ammonium), anionic (e.g. carboxylic acid, sulfonic acids) or neutral (e.g. oligoethylene glycol) in nature. The resulting amphiphilic nature of surfactants leads to a range of fascinating and valuable properties for applications in industry and nanotechnology [3], which are connected to their ability to occupy interfaces and with that lowering surface energy. For instance, for ternary systems (water, organic solvent, surfactant) they are known to effectively stabilize different kinds of emulsions. A fascinating property of surfactants

* Corresponding author. Tel.: +49 7531 884415; fax: + 497531884406.

E-mail address: sebastian.polarz@uni-konstanz.de (S. Polarz). and amphiphiles is their ability for self organization above a certain threshold concentration, the so called $\mathrm{cmc}$ (critical micelle concentra tion). The observed structures, micelles, liquid crystals and inverse phases, are also a function of the so called packing parameter intro duced by Israelachvili et al. more than 30 years ago [4]. In the meantime more advanced theories for the self assembly of surfactants and other amphiphiles such as amphiphilic block copolymers have been devel oped [5], and they consider the modes of intermolecular interaction to explain the formation of the structures. Therefore, one can eventually expect new and exciting self assembled structures, if additional interac tion modes come into play.

The latter is only one argument, why amphiphiles containing inor ganic parts are thrilling, e.g. thinking of magnetic interactions due to paramagnetic species. There are many more reasons, why it could be highly tempting to combine amphiphilic design and the concept of or ganic inorganic hybrids (see also Scheme 1). The incorporation of metal cations to the head group of an amphiphile i.e. metallosurfactant [6"], now gives interfacial surfactant systems a means to link the associ ated metal ion functionality to its amphiphilic structure. Inorganic mat ter provides numerous features (magnetism, redox variety, catalytic properties, higher electronic contrast, etc.), which are hard to realize for organics, but which would be highly desirable, if e.g. a surfactant/ amphiphile has them [ $\left.7^{*}\right]$. Thus, surfactants with inorganic constituents (I SURFs) can be seen as belonging to the larger class of so called metallomesogens [8]. The term metallomesogens was introduced by Bruce et al. for molecular species showing the ability to form liquid crystalline (LC) phases comprising coordination complexes as building blocks [9]. In most of this early work one has concentrated on systems with thermotropic LC characteristics, for instance rod like or plate like 




Scheme 1. Classification and genesis of the emerging field "hybrid surfactants and amphiphiles'.

metal compounds [10]. In the meantime, also some metal containing polymers and even inorganic particles forming LC phases or some supracrystals can be seen as belonging to metallomesogens [11\%].

However, this area still stands at the beginning and will be highlight ed in the current article. In this sense, it should be noted that the aim of our manuscript is not to give a comprehensive overview here, but we have selected some of the most important, recent developments in this emerging research field dating back to the last decade. For further discussion, it makes sense to differentiate between two classes of am phiphilic hybrids (see scheme 1), dependent on, if the system has pure molecular character (class I), or, if constituents with nanoparticle characteristics are involved (class II). Three scenarios can be discussed for class I. The simplest strategy is to start from a conventional surfac tant system (Scheme 1; Ia) and just add a metal component to it. The metal component is at most weakly bound to the surfactant. Typically, the inorganic metallic species is the counter ion of the surfactant head group (see also Section 2.1 of this paper). In alternative (Ic) the metal containing unit is the hydrophilic head group covalently linked to the hydrophobic tail. Thus, it has become an integral part of the surfactant (see Section 2.3). The situation in scenario (Ib) is somehow in between, and is best represented by a metal cation coordinated by a ligand linked to a hydrophobic chain (see Section 2.2). Hybrid amphiphilic systems can also be achieved when inorganic nanoparticles are combined with suitable molecular species as shown in Scheme 1/Ila. Another interest ing case is realized, when two different nanoparticles with different sol vent compatibilities can be joined together like shown in Scheme 1/IIb, or as a result form particles with Janus type characteristics [12]. The latter two topics will be highlighted in Section 3 of this article. It should also be noted that the assignments of the cases discussed in the following to the defined classes are not absolutely strict, but the junctions from one area to the other are rather smooth.

\section{Molecular hybrid amphiphiles}

\subsection{Surfactants with weakly bound metallic species}

It is obvious that anionic surfactants with metal cations as counter ions represent the imaginable simplest I SURF system (see Scheme 1) [13]. The first examples for I SURFs (type Ia) were presented by Mirnaya et al. back in 1989, when the LC formation of alkali metal alkanoate $\left(\mathrm{M}\left(\mathrm{OOCC}_{\mathrm{n}} \mathrm{H}_{2 n}+{ }_{1}\right)\right)$ ionic melts was discovered [14]. An interesting case was reported by Weber about the influence of self organization/packing on spin transition on Fe(II) I SURFs [15]. However, also cationic or neutral surfactants in combination with metal species deserve attention. The interaction of the cationic cetyltrimethylammonium surfactant with anionic, silicate species has led to the development of ordered mesoporous materials via the so called synergistic co assembly mechanism [16]. The hybrid surfactant/ inorganic phase forms a lyotropic liquid crystal, which acts as a template for the generation of pores. Mesoporous materials have then defined an entirely new field by themselves.

Another interesting area is the combination of anionic metal species like palladates, aluminates etc. with cationic surfactants ions [17"]. These form molecular systems that are very similar to surfactants with large, cationic heads. A nice demonstration of how the properties of the amphiphilic systems are enriched by inorganic constituents, comes from the area of ionic liquids (ILs) with metal containing counter ions [18]. Particular impressive examples have been published, when a magnetic counter ion was present [19"]. For example, Eastoe showed in a nice paper in 2012 how magnetic ILs could be used to establish responsive surface properties [20]. Also other, less common counter ions like ferrocenyl anions can be used [21]. Some spectacular results, which deserve special attention, could be obtained by using the so called polyoxometalates (POMs) as negative counter anions for cationic ammonium surfactants [22].

POMs consist of multinuclear metal oxide building blocks $\left[\mathrm{MO}_{\mathrm{x}}\right]$ and are widely known for their interesting properties in catalysis and mag netism [23"]. Because polyoxometalates as a class includes thousands of specific compounds, it is beyond the scope of the current paper to give a comprehensive overview of the POM field [23a]. POM SURF hybrid systems represent excellent examples for so called surfactant encapsulated clusters (SECs). Kurth and co workers created SECs by re placing the counter cations of anionic molybdovanadato POMs by long alkyl chained cationic ammonium surfactants [22b,24]. A close packing of the alkyl chains was observed, and it was concluded that there is a compact shell around the POM. The surfactant shell improves the stabil ity of the embedded POM and its solubility in nonpolar, aprotic organic solvents. Our group presented a unique system [22e], which was some years later "adapted" by Cronin and coworkers [25]. Giant, donut shaped POMs were treated with a cationic, double tailed surfactant. It was found that the surfactant binds exclusively on the periphery of the inorganic POM cluster. A novel species forms with special, quadru polar amphiphilic properties (hydrophilic, hard, inorganic core and hy drophobic, soft, organic shell). Self organization into columnar lyotropic liquid crystal (LLC) phases was reported. Noro et al. used a very similar system to demonstrate gas and vapor adsorption and catalytic proper ties in addition to the self organization properties [25]. In recent time surfactant complexes with smaller POM cores like the Keggin structure have moved into the focus of research. Zhang reported in 2013 the re versible redox controlled switching of the morphology of a SEC contain ing the $\left[\mathrm{Mo}_{6} \mathrm{O}_{19}\right]^{2-}$ (see Fig. 1) [26]. This example gives an idea of the complex self assembly characteristics and opens the door for manifold adjusting for tailor made liquid crystal phases, as not only the encapsu lating surfactant but also the core can have an impact on self assembly behavior. Wu and Wang contributed extensively on this topic with their 
a)

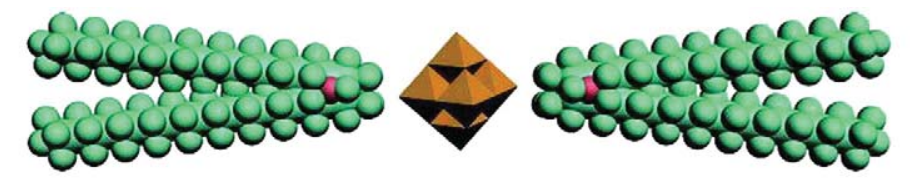

b)
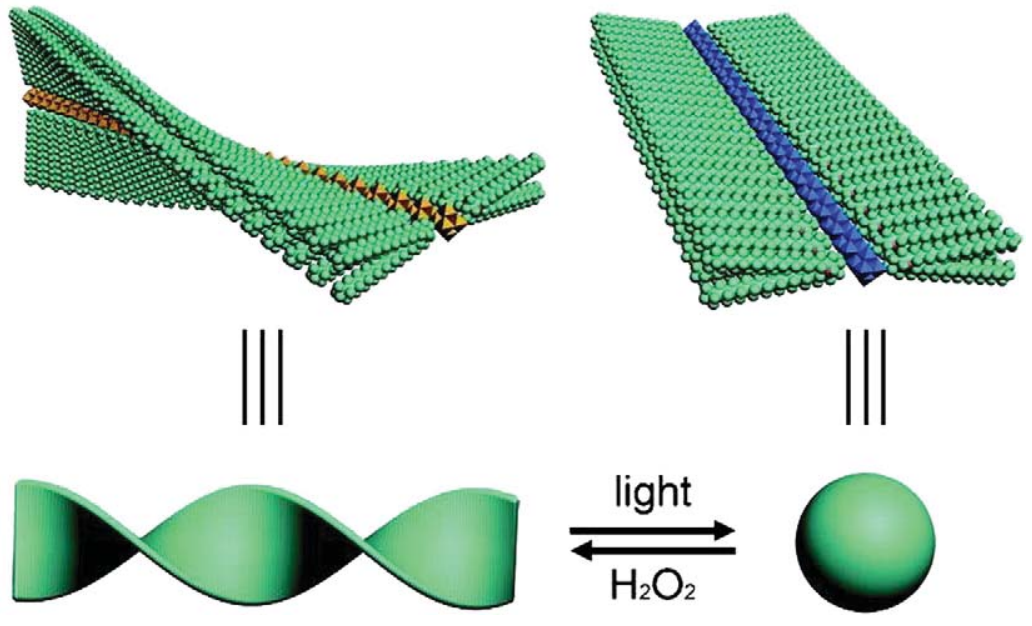

Fig. 1. Schematic of (a) chemical structure of (DODA) $2\left[\mathrm{Mo}_{6} \mathrm{O}_{19}\right]$ and (b) reversible morphological transformation between helical and spherical assemblies upon UV light reduction and $\mathrm{H}_{2} \mathrm{O}_{2}$ oxidation. Reproduced from Ref. [26] with permission. Copyright 2013, Wiley-VCH.

publications discussing the liquid crystalline systems. They also increased the complexity of the encapsulated cluster as they use additional transition or rare earth metal substituted POMs [27].

\subsection{Amphiphilic ligands with coordinated metals}

The access to new hybrid surfactants with a head group containing one single metal center is straightforward at first glance. The basic idea is that a charged metal complex fragment coordinates to a chelat ing, organic ligand, which is modified by one long alkyl chain. At second glance it becomes apparent that the latter approach is quite demanding. The successive reaction of the metal with a second ligand is generally not preferred, because it leads to compounds with less dipolar and enhanced hydrophobic character. Consequently, for obtaining I SURFs it is favorable if the metal prefers low coordination numbers or the ligand contains a rather high number of chelating donor centers. Further difficul ties arise, because it is actually not so easy to prepare asymmetric molec ular species. The preparation of the required organic ligands can be quite tedious, and it might be difficult to attach only one hydrocarbon chain.

Macrocyclic cavities such as tetraazamacrocycles are known for complexing various metal cations making them suitable as potential head groups. Over the last decades several methods have been developed for functionalization towards mono alkylation of tetraazamacrocycles or other macrocycles [28]. First examples for the resulting hybrid amphi philes, were given by Le Moigne et al., who were able to combine the metal binding properties of crown ethers with surfactant design [29].



Fig. 2. Conversion between nanoslices (2D), nanorods (1D) and nanospheres (0D) of an amphiphilic Zn(II)-complex. Reprinted (adapted) with permission from Ref. [35]. Copyright (2012) American Chemical Society. 
A similar surfactant system and its self organization behavior could be presented by Neve et al. [30]. Later Bruce et al. introduced the pioneering concept to use bipyridine derivatives and related com pounds as ligands for the synthesis of I SURFs/type Ib (see Scheme 1) [31]. A double tailed surfactant with the vanadyl cation as a magnetic transition metal center was presented by Zhu and Swager [32]. Binnemans et al. have investigated the preparation of surfactants con taining lanthanides. They presented tailor made ligands characterized by seven donor centers encapsulating the metal ion [13b,33*" . Another nice example is a $\mathrm{Tb}(\mathrm{III})$ containing metallosurfactant showing an in crease of luminescence as a result of chemical binding of nucleotides $\left[34^{\circ}\right]$. This made it possible to monitor biological processes as it has been observed that the luminescence from the $\mathrm{Tb}$ (III) showed a (127 fold) increase due to light energy absorbed by a guanine group of gua nine triphosphate and transferred to the $\mathrm{Tb}(\mathrm{III})$ center. The nucleotides are able to bind at the vesicular surface and so a sensing system is created, which makes it possible to track the GTP (guanosine 5' triphosphate) to GDP (guanosine $5^{\prime}$ diphosphate) conversion. This would not be possible with a classical organic amphiphile, and it is purely due to the nature of the inorganic metal ion that these amphi philic systems exhibit such interesting properties.

The self assembly of a $\mathrm{Zn}$ (II) containing metallosurfactant can re versibly tune via controlled axial coordination of zinc porphyrin with $4,4^{\prime}$ bipyridine, which results in 0D, 1D, and 2D structures (see Fig. 2) [35]. This hybrid surfactant has the ability to form different self assembled structure based on the metallosurfactants intramolecular interaction with different solvent that results into the controlled aggrega tion between nanorods, nanospheres and nanoslices based on a desired solvent combination used [35]. A Ru(II) polypyridyl porphyrin conjugate amphiphile, combines photo induced charge separation and enhanced cellular uptake properties into a single amphiphilic system as an effective photodynamic therapeutic anticancer agent $\left[36^{\circ}\right]$. Another interesting study was published by Iza et al. in 2015. Superior control over the aggre gation behavior of a Ru(II) metallosurfactant could be achieved by further influence of cyclodextrins sliding off and on the hydrophobic chain [37]. A novel idea was presented in a paper by Schubert et al., who have linked two parts with different solvent compatibilities to each other via $\mathrm{Ru}(\mathrm{II})$ resulting in a unique hybrid block copolymer compound [38].

An investigation of the dynamics process that occurs during stem cell tracking has been achieved via positron emission tomography (PET) in vivo with hexadecyl modified DOTA $(1,4,7,10$ tetraazacyclododecane tetraacetic acid) benzoate labeled with the radioactive nuclide ${ }^{64} \mathrm{Cu}$, which incorporates into a stem cell membrane and allows in vivo observation [39]. These findings are of outstanding interest, because they provide insight in distribution and dynamics in vivo without affect ing the cell viability in a negative manner. In a case presented by our group, a magnetically susceptible dysprosium Dy(III) cation chelated to a long alkyl chained DOTA ligand, self assembled in panoscopic architecture in nano to macrometer range (see Fig. 3) as a result of the existing magnetic interaction [40]. The orientation dependence with respect to an externally applied magnetic field has a high potential for use in liquid crystal display (LCD) applications and magnetically triggered drug delivery. In addition, the ability to trigger self assembly using an externally applied magnetic field opens a door for the possibility of using different magnetic field strengths to study the aggregation and dynamic of molecular self assembly. Other I SURFs containing strong paramagnetic ions have been of interest due to their potential as contrast agents in magnetic resonance imaging (MRI) rath er than for their self assembly properties [41].

Some rare cases of surfactants containing organometallic species (C metal bonds) were described. Many of these compounds comprise com plexes with $\mathrm{Cp}$ (cyclopentadienyl anion) due to their sufficient stability in protonic solvents, ultimately in water. Li et al. described a Rh Cp I SURF used in enantioselective catalysis [42]. An inverted, hydropho bic hydrophilic motif was presented by Shen et al. with an I SURF con taining ferrocene in the hydrophobic moiety [43]. Fascinating work was also presented by Gohy et al. on ferrocenylsilane block copolymers showing numerous amphiphilic properties [44]. We succeeded in the preparation of another organometallic I SURF containing an alkyl alkoxy zinc cluster attached to two polyethylene glycol as a polar chain $\left[45^{\circ}\right]$. Interestingly, this new organometallic amphiphile self assembles over several length scales. First, the dimers form a lamellar phase via a microphase separation of the hydrophobic oxo cluster enti ties and the polar PEG domains indicated by polarization microscopy, SAXS and TEM [ $\left.45^{\circ}\right]$. In contact with apolar solvents like toluene swell ing of the hydrophobic domains and further structuring occurs surprisingly into relatively monodisperse spheres.

These spheres agglomerate into a close packing structure, which due to the dimension of the single spheres ( $200 \mathrm{~nm}$ in size) behaves like an optical grating diffracting light in the visible range. The latter leads to the emergence of blue color, although the system does not contain any chromophore. In comparison to traditional amphiphiles, the discussed system is also different because it contains an additional func tion: the ability to act as a precursor for $\mathrm{ZnO}\left[45^{\circ}\right]$. Indeed, a bimodal, macro nano porous $\mathrm{ZnO}$ could be generated directly from the nano structured gel and the morphology of the $\mathrm{ZnO}$ was directly influenced by the morphology of the $[\mathrm{MeZnOPEG}]_{2}$ phase.

\subsection{Surfactants with pure inorganic heads}

Examples of surfactants with purely inorganic head groups (Scheme 1; type Ic) are much more rare, and the first cases have been published only very recently. The attachment of multinuclear transition metal entities as head to an organic alkyl chain is very difficult because many M X linkages ( $\mathrm{X}=\mathrm{C}, \mathrm{O}, \mathrm{N}$ ) are susceptible to hydrolysis. Obviously, cleavage of the alkyl chain in water would destroy any amphiphilic properties.

However, recent activity in the field of polyoxometalate chemistry (POM) delivered some highly innovative surfactant species that were stable in water, and some nice studies about their self assembly have been published [46]. An important step towards monomolecular POM amphiphiles is the capability of a controlled organic modification of POM clusters to create a fixed amphiphilic molecule. The main route for heteropolyoxometalates starts from lacunary species. Those clusters are lacking one or more $[\mathrm{M}=\mathrm{O}]$ units and therefore present reactive oxygen atoms, where negative charge is localized. At those sites organic groups can easily be attached via condensation reactions. A detailed discussion of functionalization of polyoxometalates would go far beyond the scope of this article. Further information on this topic is provided by Proust et al. and Dolbecq et al. [23b,47].

An early amphiphilic POM system starting from a tris (hydroxymethyl)aminomethane (TRIS) modified Mn Anderson POM was presented by Zhang et al. [48]. Two alkyl chains were capped onto each site of the $\left[\mathrm{MnMo}_{6} \mathrm{O}_{24}\right]$ cluster via amide bonds. It was shown that the amphiphilic system self assembles into large vesicular structures. This was the first example for POM amphiphiles arranging in vesicles. However, the latter system has two disadvantages. The am phiphile is insoluble in water due to the presence of the bulky tetrabutylammonium ions. Self assembly could only occur when signif icant amounts of acetonitrile were added. Furthermore, the geometry of the amphiphile is unfavorable with respect to the ideal dipolar charac ter of a surfactant, because the hydrophobic tails are symmetrically attached on each site of the head group. As a consequence, the tails have to bend significantly to form a vesicular structure. This makes the vesicle formation more difficult and the self assembly process takes more time compared to classical surfactants. Nevertheless, an amphiphile possessing the latter geometry is more appropriate to self assemble in apolar solvents to form reverse aggregates [49].

Our group has presented polyoxometalate I SURFs with a lacunary $\left[\mathrm{PW}_{11} \mathrm{O}_{39}\right]$ head group [50]. It could be shown that this system has all functionalities of classical surfactants, like the ability to form micelles, emulsions, lyotropic liquid crystals, monolayers at the water/air 
g)

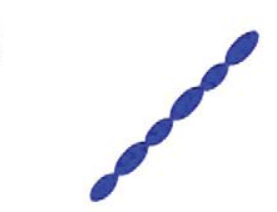

f)

e)

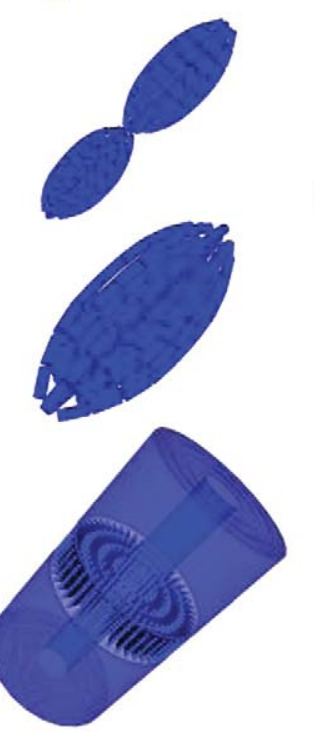

d)

c)

b)
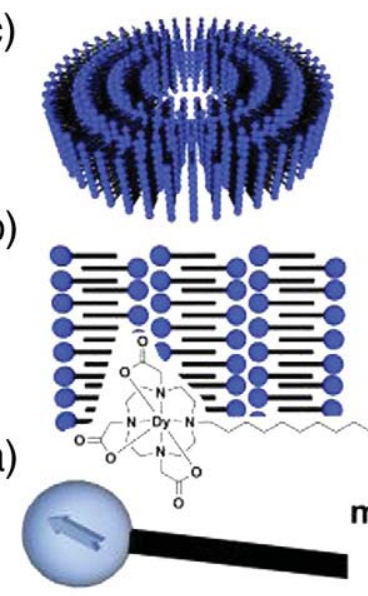
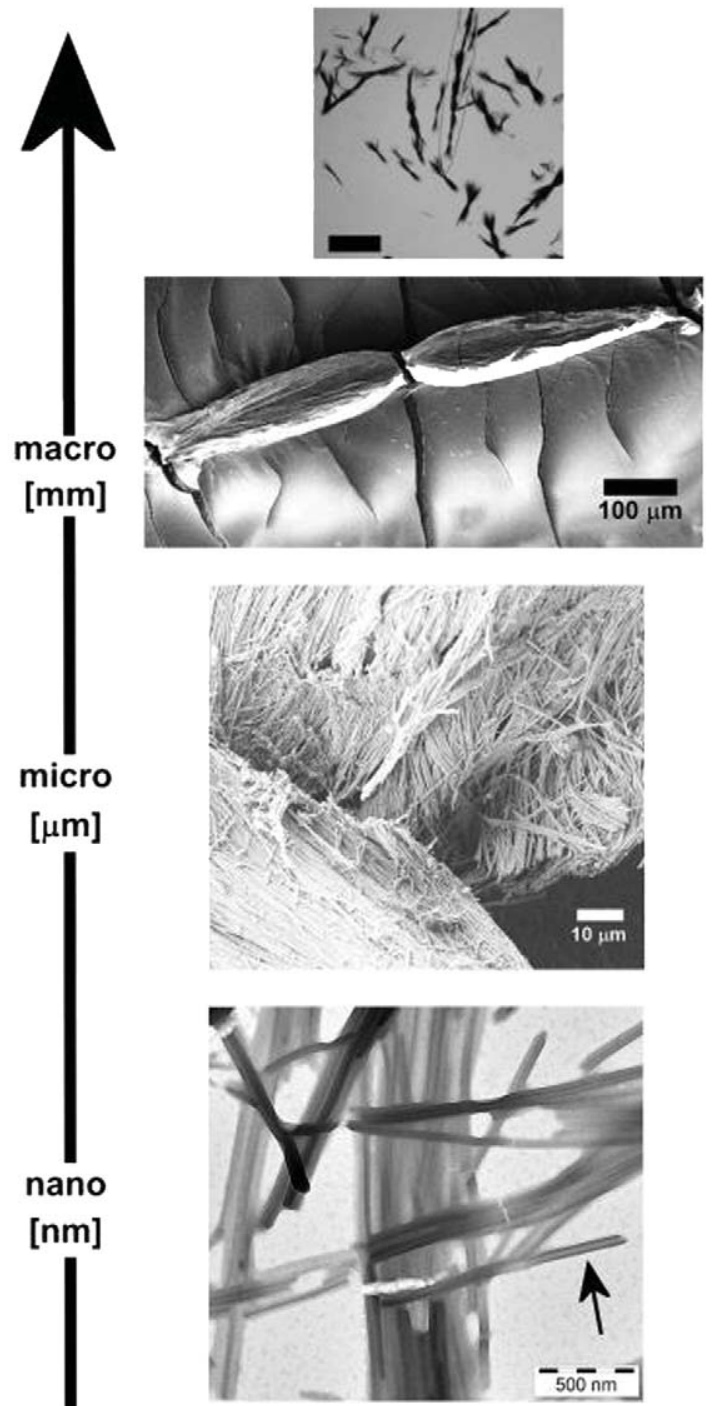

Fig. 3. Panoscopic architecture resulting from the hierarchical self-organization of [Dy- $\mathrm{C}_{10} \mathrm{DOTA}$ ] and some corresponding analytical data (TEM, SEM, optical microscopy) [40]. (a) The magnetic moment located at the head group is indicated. b) Lamellar structures with interdigitating inorganic surfactants. c, d) Hollow fibers with multilamellar substructure. e) Tactoid. f) Tactoid dumbbell. g) Chains of tactoids.

interface and also ultra small monolayer vesicles [51]. The observation of all of the latter structures is aided by the enormous electronic contrast of the tungstate head group [52]. A nice demonstration for the addition al functionality of hybrid surfactants was discussed by us in 2012 [53], when the redox properties of a bimetallic Ru POM I SURF were ana lyzed. It was shown that the charge of the head group could be varied reversibly from $-1 \leftrightarrow-2 \leftrightarrow-3 \leftrightarrow-4$. This unique property of the surfactant enabled triggering of the mode of self assembly via electro chemistry [53]. It goes without saying that the introduction of the polyoxometalate as a head group of an amphiphile has broadened the chemical and physical properties of amphiphiles tremendously and this has opened a door to quite a broad range of applications.

Alternative inorganic entities might be used for the creation of new hybrid surfactants, when linkages stable against water can be used. Two candidates can be identified from the current literature: polyhedral oligomeric silsesquioxane (POSS) and fullerenes. It should be noted that the simple hydrophobic hydrophilic balance can no longer be applied here directly, because POSS and fullerenes are characterized by substan tial hydrophobicity themselves. Therefore, it is important that the at tached side chains are different concerning their solvent compatibility. The most common POSS used consists of eight RSiO units that form a highly soluble cage like structure with corner groups that are accessible for further functionalization [54], for instance with polyethylene oxide (PEO) as a polar group [55]. The amphiphilic character created this way also leads to interesting self organization behavior as reported in several other recent publications [56].

Fullerenes, with $\mathrm{C}_{60}$ as the most prominent example, are inorganic molecules, which however can be used in organic reactions. They behave like linearly conjugated alkenes, with respect to their chemical reactivity. This makes it possible to apply the addition chemistry known for CC double bonds. Fullerene derivatives that bear aliphatic chains have recently emerged as a new class of hybrid "hydrophobic surfactants' and the concept was recently discussed by Nakanishi, Schenning et al. and Asanuma et al. $\left[57^{*}, 58\right]$. The individual head and 
tail groups of these amphiphiles are both hydrophobic making these amphiphiles insoluble in water. However, these alkyl fullerenes are compatibility in alkyl or aromatic solvents due to the different solvent affinities of the alkyl and fullerene groups of these two solvent types. Note the different self assembled structures shown in Fig. 4 [58a,59]. The amphilicity of these alkyl fullerenes arises furthermore due to the electronic gradient between the rigid fullerene head and flexible tail groups. This gradient between head and tail groups results in different solvophobic interactions allowing these amphiphiles to self assemble into different structures. In solution the alkyl fullerene amphiphiles self assemble to minimize contact to its solvophobic parts with the solvent. It is therefore believed that the improved solubility of these hybrid surfactants is caused by the mentioned clustering, which results in unfavorable interactions between the fullerene head group and n alkane molecules [59b].

Furthermore, the self organization of alkyl fullerenes is also governed by a gentle balance between weak $\pi \pi$ interactions between fullerene head groups and van der Waals intermolecular forces among neighboring hydrocarbon alkyl chains. It is due to these weak interac tions that it is possible for this class of amphiphiles to display polymor phism under various externally applied factors such as temperature, solvation effects and concentration, which is an extremely rare phe nomenon (see Fig. 5) [57,60]. The self assembly morphologies of alkyl fullerenes range from monolayers [61"], bilayer vesicles [59a,62], nanorods and wires [63], thin disks, fibrous, columnar liquid crystal [64], and room temperature liquids [65], to name only a few. Alkyl fullerene systems have potential for multiple molecular and self assembly applications ranging from antioxidant capacity [66], small molecule based bulk heterojunction (BHJ) organic solar cell devices [67], nanocapsules with potential applications as drug delivery systems [68], and emerging photovoltaic and optoelectric devices [69]. It can be concluded that it is appropriate to classify alkyl fullerenes as hybrid amphiphiles, despite the fact that they do not possess the classical hydrophobic/hydrophilic d block molecular architecture of surfactant used in water.

\section{Particle-based hybrid amphiphiles}

It is well known that particles themselves are interfacial active, which is the basis for the formation of pickering emulsions or play a role in important applications like flotation [70"*]. However, in line with Scheme 1, here, we only want to consider systems containing at least one nanoparticle and characterized by a substantial amphiphilic, dipolar character, respectively a substantial difference in solvent com patibility. Often these systems are described in the literature as Janus particles, a topic which has already been reviewed extensively in the lit erature [71]. The term 'Janus' describes anisotropic entities by coupling two or more dissimilar components at a small junction, exposing two regions for optimal expression of their combined functionalities.

\subsection{Organic inorganic particle hybrids}

In case the linkage between the nanoparticle and the molecular spe cies to attach is very strong, like for covalent bonds, various methodol ogies have been developed for modification of only one side of a particle [71]. For instance, one can immobilize the particle on a sub strate, and only its opposite surface is accessible to modifications. How ever, in most cases the interaction between surfaces of solid inorganic materials and organic compounds has a dative character between low coordinated surface centers (e.g. metal cations) and donor groups in the organic additive (e.g. $-\mathrm{COO}^{-}$). Because this kind of linkage can be weak, and highly reversible in character, it has proven to be quite difficult to prepare hybrid amphiphiles type Ila (see Scheme 1) using inorganic particles, because sooner or later there would be an equally distributed organic shell all around the particle. It is very hard to main tain an anisotropic distribution. However, two strategies exist, which have to be explored much further in future research.

It is well known that nanocrystals have different surfaces corre sponding to different facets of the crystal lattice [11g]. Eventually this can lead to a different density of organic capping agents attached to the different surfaces. As a result there may be a slight anisotropy and amphiphilic character leading to self assembly and the formation of or dered particle superstructures, resembling liquid crystals [72]. Another approach is, if it is possible to partially modify one particle exclusively only with one organic molecule (see Scheme 1/IIa). For larger nanopar ticles it is extremely hard to secure that only one species interacts with the surface by avoiding multiple bonding. However, when the inorganic particles are very small, e.g. for inorganic clusters, some successful and interesting cases have been reported in the literature. For instance Fujii et al. have described in 2013, how one side of a $2 \mathrm{~nm} \mathrm{Au}$

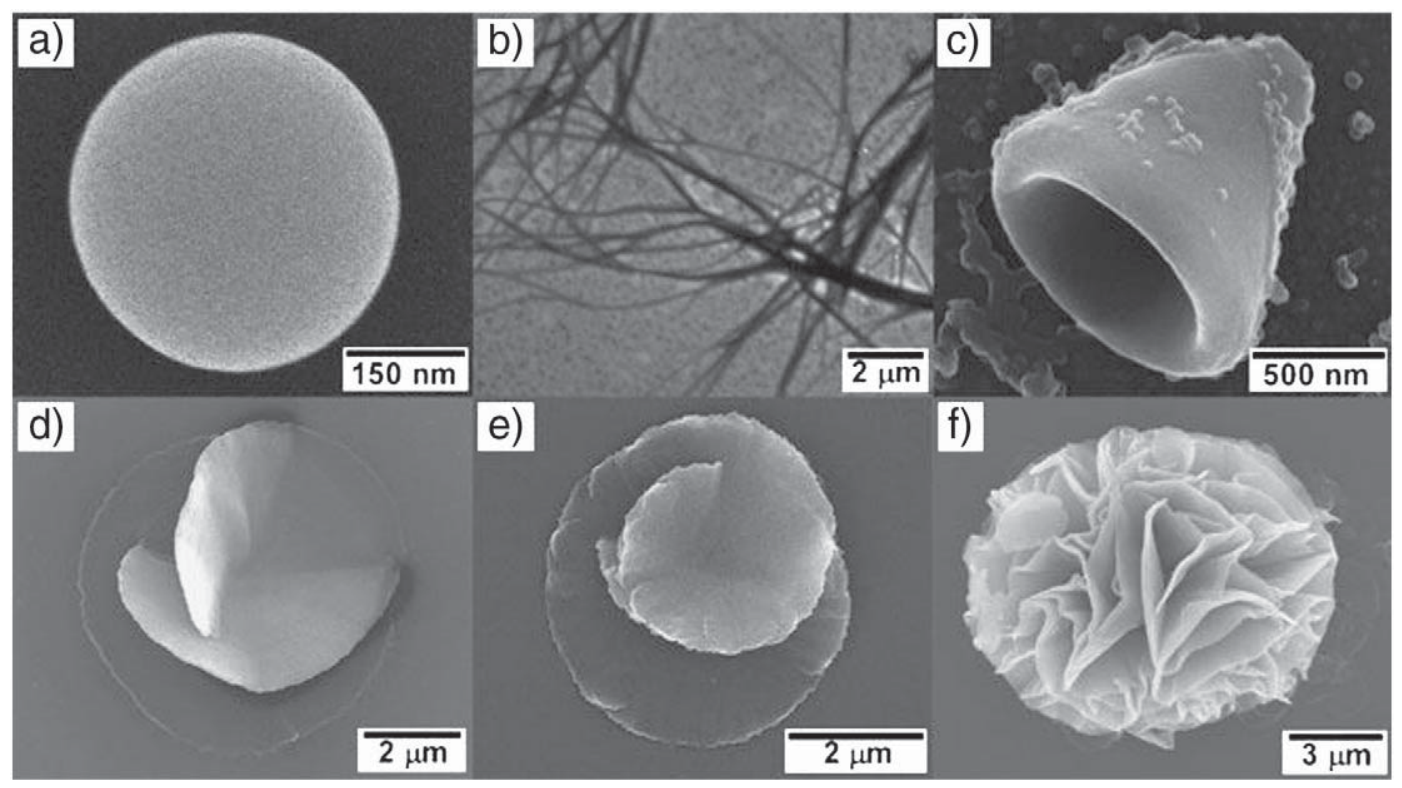

Fig. 4. SEM images of fulleropyrrolidine with 3,4,5,-(hexadecyloxy) phenyl) amphiphile displaying self-assembly polymorphism (a) vesicular in 2-propanol/toluene, (b) fibrous in 1-propanol, (c) cone-shaped in water/THF (d) left-handed, (e) right-handed spiral object in 2-(R)-butanol and 2-(S)-butanol respectively, and f) flowerlike assemblies in 1,4-dioxane at $60{ }^{\circ} \mathrm{C}$. Reprint with permission from Ref. [57”] , Copyright (2010) Royal Society of Chemistry and Copyright 2007, Wiley-VCH. 


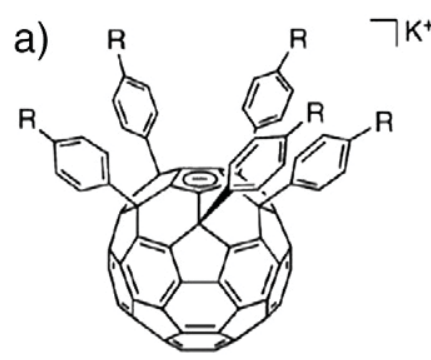

b)

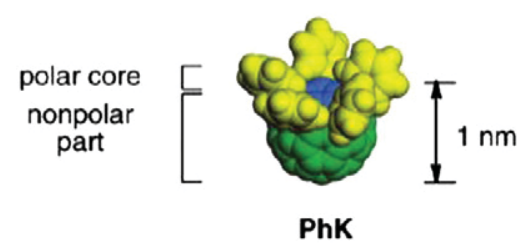

e)



c)

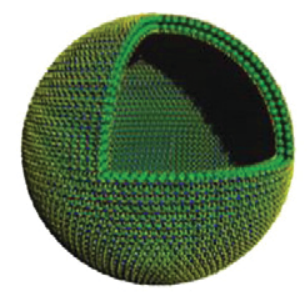

f)

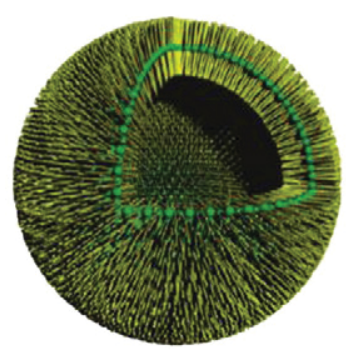

d)



g)

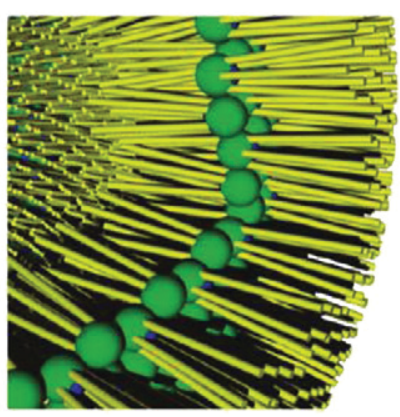

Fig. 5. Schematic images of vesicles made of fullerene anione of surfactatnts s. (a) Chemical structures of potassium complexes of fullerene anions. (b) CPK drawing of PhK. (c) Schematic model of bilayer vesicle of PhK. (d) A magnified image of the bilayer PhK vesicle. (e) CPK drawing of C20K. (f) Schematic model of a vesicle of C20K. (g) A magnified image of the interdigitated bilayer of the C20K vesicle. The fullerene parts are shown in green, the hydrophilic parts in blue, and substituents in yellow. Reprinted with permission from Ref. [35]. Copyright (2011) American Chemical Society.

nanoparticle was stuck inside the cavity of a cysteine modified calixarene [73]. The novel hybrid compound had amphiphilic properties and showed interesting self assembly features. Very recently Yao et al. showed that the capping agents around an $\mathrm{Au}_{25}$ could be switched from an isotropic distribution around the cluster core, to an anisotropic state with amphiphilic character [74].

\subsection{Particle particle Janus systems}

Much more cases have been reported for the combination of two types of particles with each other, often resulting in amphiphilic proper ties. The number of combinations is almost endless with organic organic, organic inorganic and inorganic inorganic representing only the major classes [71]. However, it is very difficult to join exactly two different particles together to a new hybrid amphiphile (case IIb in Scheme 1). Frequently, one finds in the literature reports about hybrid particles formed by the assembly of several nanoparticles gaining amphiphilicity via a partial microphase separation. A good example for the latter is Janus particles bearing organic inorganic composite such as $\mathrm{Fe}_{2} \mathrm{O}_{3}$ and $\mathrm{TiO}_{2}$, self assembled into dual phase quasi spherical material via intro ducing amphiphilic polymers [75]. The amphiphilic nature of these par ticles allows the formation of stable dispersions and higher aggregates in solution.

Only few and very recent examples should be discussed here for sit uation IIb (Scheme 1). One example is on dumbbell shape amphiphilic Janus $\mathrm{Au}\left(\mathrm{Fe}_{3} \mathrm{O}_{4} @ \mathrm{SiO}_{2}\right)$ nanoparticles [76], with tunable wettability and enhanced catalytic properties. The system is capable of cell internal ization, which is making it a good material for application in the field of magnetic resonance imaging (MRI) and drug delivery. Furthermore, the availability of anisotropic magnetic susceptibility allows the manipula tion of the particle orientation interaction with respect to an externally applied electric and magnetic field inducing rotational motion relative to the applied field. This offers a means to influence the mode of self assembly of these systems due to the inorganic constituent. Li et al. showed in 2014, how an interesting $\mathrm{Fe}_{3} \mathrm{O}_{4}$ graphene hybrid amphiphile can be prepared, and they indicated how the material could be applied as novel supercapacitors [77]. The amphiphilic properties of $\mathrm{Au}^{\mathrm{Fe}} \mathrm{O}_{3}$ Janus nanoparticles were studied by Sahoo et al. in an impressive paper, showing their ability for the colloidal stabilization of $\mathrm{WS}_{2}$ nano tubes $\left[78^{\circ}\right]$. Very unusual modes of self assembly and superstructure formation were reported by Zhao et al. for a hybrid amphiphile composed of Au and CdSe [79].

\section{Conclusions}

Despite the fact, that only several cases were highlighted here, the previous paragraphs have clearly shown that the creation and investiga tion of hybrid amphiphiles are an emerging topic with high potential. Researcher could already obtain some fascinating results. Compared to pure organic surfactants and amphiphiles, one can see that the mode of self assembly is often more complex, sometimes spans several length scales. This is mostly due to additional intermolecular interactions 
between the constituents different to van der Waals and electrostatics only. Furthermore, it could be seen that numerous cases exist, showing that there is not only a combination of amphiphilic features with the properties of the inorganic constituent (e.g. special electronic, catalytic properties, etc.), but that the hybrid materials have new characteristics that none of the single components have by themselves, e.g. certain stimuli responsive properties. Thus hybrid amphiphiles are truly fulfill ing their promise for the existence of emergent phenomena and system ic features.

\section{Acknowledgments}

We thank the European Research Commission (ERC) for funding (ERC Consolidator Grant I SURF). We also thank the National Research Foundation (NRF) South Africa for Dr. James A. Odendal postdoctoral DST Innovation Postdoctoral Fellowships: SFP 13081428099.

\section{References $^{1}$}

[1] (a) Clerc M, Kennedy J. The particle swarm-explosion, stability, and convergence in a multidimensional complex space. IEEE Trans Evol Comput 2002;6:58-73.

(b) Jadbabaie A, Lin J, Morse AS. Coordination of groups of mobile autonomous agents using nearest neighbor rules. IEEE Trans Autom Control 2002;48:988-1001.

[2] (a) Sanchez C, Julian B, Belleville P, Popall M. Applications of hybrid organicinorganic nanocomposites. J Mater Chem 2005;15:3559-92.

(b) Sanchez C, Soler-Illia G, Ribot F, Lalot T, Mayer CR, Cabuil V. Designed hybrid organic-inorganic nanocomposites from functional nanobuilding blocks. Chem Mater 2005;13:3061-83.

(c) Zou H, Wu SS, Shen J. Polymer/silica nanocomposites: preparation, characterization, properties, and applications. Chem Rev 2005;108:3893-957.

[3] Rosen MJ, Dahanayake M. Industrial utilization of surfactants: principles and practice. AOCS Press; 2000.

[4] Israelachvili JN, Mitchell DJ, Ninham BW. Theory of self-assembly of hydrocarbon amphiphiles into micelles and bilayers. J Chem Soc Faraday Trans 1976;72:1525-68.

[5] (a) Southall NT, Dill KA, Haymet ADJ. A view of the hydrophobic effect. J Phys Chem B 2002;106:521-33.

(b) Mai YY, Eisenberg A. Self-assembly of block copolymers. Chem Soc Rev 2002;41: 5969-85.

(c) Riess G. Micellization of block copolymers. Prog Polym Sci 2002;28:1107-70.

(d) Chandler D. Interfaces and the driving force of hydrophobic assembly. Nature 2002;437:640-7.

[6] Griffiths PC, Fallis IA, Chuenpratoom T, Watanesk R. Metallosurfactants: interfaces and micelles. Adv Colloid Interf Sci 2006;122:107-17.

[7] (a) Polarz S, Landsmann S, Klaiber A. Hybrid surfactant systems with inorganic constituents. Angew Chem Int Ed 2014:53:946-54.

(b) Mann S. Self-assembly and transformation of hybrid nano-objects and nanostructures under equilibrium and non-equilibrium conditions. Nat Mater 2014;8:781-92

[8] (a) Giroudgodquin AM, Maitlis PM. Metallomesogens-metal complexes in organized fluid phases. Angew Chem Int Ed 1991:30:375-402.

(b) Hudson SA, Maitlis PM. Calamitic metallomesogens-metal containing liquidcrystals with rodlike shapes. Chem Rev 1991;93:861-85.

[9] Maitlis PM, Bruce DW, Dhillon R, Dunmur DA, Fanizzi FP, Hunt SE, et al. Metallomesogens-organometallic and coordination-complexes with liquid-crystalline properties. Can J Chem 1990;14:549-51.

[10] (a) Bedard TC, Moore JS. Design and synthesis of a molecular turnstile. J Am Chem Soc 1995;117:10662-71.

(b) Bruce DW. Calamitics, cubics, and columnars-liquid-crystalline complexes of silver(I). Acc Chem Res 1995;33:831-40.

[11] (a) Oriol L, Serrano JL. Metallomesogenic polymers. Adv Mater 1995;7:348-69.

(b) Liu XH, Bruce DW, Manners I. Novel calamitic side-chain metallomesogenic polymers with ferrocene in the backbone: synthesis and properties of thermotropic liquid-crystalline poly(ferrocenylsilanes). Chem Commun 1995:289-90

(c) Whittell GR, Manners I. Metallopolymers: new multifunctional materials. Adv Mater 1995;19:3439-68.

(d) Sonin AS. Inorganic lyotropic liquid crystals. J Mater Chem 1995;8:2557-74.

(e) Rogach AL, Talapin DV, Shevchenko EV, Kornowski A, Haase M, Weller H. Organization of matter on different size scales: monodisperse nanocrystals and their superstructures. Adv Funct Mater 1995;12:653-64.

(f) Ozin GA. Panoscopic materials: synthesis over 'all' length scales. Chem Commun 1995:419-32.

(g) Polarz S. Shape matters: anisotropy of the morphology of inorganic colloidal particles-synthesis and function. Adv Funct Mater 1995;21:3214-30.

[12] Perro A, Reculusa S, Ravaine S, Bourgeat-Lami EB, Duguet E. Design and synthesis of Janus micro- and nanoparticles. J Mater Chem 2005;15:3745-60.

[13] (a) Binnemans K. Ionic liquid crystals. Chem Rev 2005;105:4148-204.

${ }^{1}$ References with $\left({ }^{*}\right)$ are of special interest and those with $\left({ }^{* *}\right)$ are of outstanding interest in the context of this review as Amphiphilic hybrids containing inorganic constituent. (b) Binnemans K, Görller-Walrand C. Lanthanide-containing liquid crystals and surfactants. Chem Rev 2005;102:2303-46.

(c) Donnio B. Lyotropic metallomesogens. Curr Opin Colloid Interface Sci 2005;7: 371-94.

[14] Mirnaya TA, Prisyazhnyi VD, Shcherbakov VA. Liquid-crystal state of salt fusions with organic ions. Usp Khim 1989;58:1429-50.

[15] Tyagi R, Malhotra S, Thunemann AF, Sedighi A, Weber M, Schafer A, et al. Investigations of host-guest interactions with shape-persistent nonionic dendritic micelles. J Phys Chem C 2013;117:12307-17.

[16] (a) Huo QS, Margolese DI, Ciesla U, Feng PY, Gier TE, Sieger P, et al. Generalized synthesis of periodic surfactant inorganic composite materials. Nature 1994;368: 317-21.

(b) Monnier A, Schuth F, Huo Q, Kumar D, Margolese D, Maxwell RS, et al. Cooperative formation of inorganic-organic interfaces in the synthesis of silicate mesostructures. Science 1994:261:1299-303.

(c) Polarz S, Smarsly B. Nanoporous materials. J Nanosci Nanotechnol 1994;2: 581-612.

(d) Soler-illia GJD, Sanchez C, Lebeau B, Patarin J. Chemical strategies to design textured materials: from microporous and mesoporous oxides to nanonetworks and hierarchical structures. Chem Rev 1994:102:4093-138.

(e) Yang PD, Zhao DY, Margolese DI, Chmelka BF, Stucky GD. Generalized syntheses of large-pore mesoporous metal oxides with semicrystalline frameworks. Nature 1994;396:152-5.

[17] (a) Welton T. Room-temperature ionic liquids. Solvents for synthesis and catalysis. Chem Rev 1999;99:2071-83.

(b) Dupont J, de Souza RF, Suarez PAZ. Ionic liquid (molten salt) phase organometallic catalysis. Chem Rev 1999;102:3667-91.

[18] (a) Zhang P, Gong Y, Lv Y, Guo Y, Wang Y, Wang C, et al. Ionic liquids with metal chelate anions. Chem Commun 2012:48:2334-6.

(b) Wang H, Wang J, Zhang S, Xuan X. Structural effects of anions and cations on the aggregation behavior of ionic liquids in aqueous solutions. J Phys Chem B 2012; 112:16682-9.

[19] (a) Santos E, Albo J, Irabien A. Magnetic ionic liquids: synthesis, properties and applications. RSC Adv 2014:4:40008-18.

(b) Degen P, Zwar E, Paulus M, Tolan M, Rehage H. About the role of surfactants on the magnetic control over liquid interfaces. Langmuir 2014;30:11563-6.

[20] Brown P, Bushmelev A, Butts CP, Cheng J, Eastoe J, Grillo I, et al. Magnetic control over liquid surface properties with responsive surfactants. Angew Chem Int Ed 2012:51:2414-6.

[21] Li QH, Chen X, Yue X, Huang DD, Wang XD. Construction and transformation of stimuli-responsive vesicles from the ferrocene derivative supramolecular amphiphiles. Colloids Surf A Physicochem Eng Asp 2012;409:98-104

[22] (a) Coronado E, Gomez-Garcia CJ. Polyoxometalate-based molecular materials. Chem Rev 1998:98:273-96

(b) Kurth DG, Lehmann P, Volkmer D, Cölfen H, Koop MJ, Müller A, et al. Surfactantencapsulated clusters (SECs): (DODA) $)_{20}\left(\mathrm{NH}_{4}\right)\left[\mathrm{H}_{3} \mathrm{Mo}_{57} \mathrm{~V}_{6}(\mathrm{NO})_{6} \mathrm{O}_{183}\left(\mathrm{H}_{2} \mathrm{O}\right)_{18}\right]$, a case study. Chem Eur J 1998;6:385-93.

(c) Li H, Sun H, Oi W, Xu M, Wu L. Onionlike hybrid assemblies based on surfactantencapsulated polyoxometalates. Angew Chem 1998;46:1300-3.

(d) Nisar A, Wang X. Surfactant-encapsulated polyoxometalate building blocks: controlled assembly and their catalytic properties. Dalton Trans 1998;41: 9832-45.

(e) Polarz S, Smarsly B, Antonietti M. Colloidal organization and clusters: selfassembly of polyoxometalate-surfactant complexes towards three-dimensional organized structures. ChemPhysChem 1998;2:457-61.

(f) Bu W, Uchida S, Mizuno N. Micelles and vesicles formed by polyoxometalateblock copolymer composites. Angew Chem 1998;48:8281-4.

[23] (a) Long DL, Burkholder E, Cronin L. Polyoxometalate clusters, nanostructures and materials: from self assembly to designer materials and devices. Chem Soc Rev 2007;36:105-21.

(b) Proust A, Thouvenot R, Gouzerh P. Functionalization of polyoxometalates: towards advanced applications in catalysis and materials science. Chem Commun 2007:1837-52.

[24] Caruso F, Kurth DG, Volkmer D, Koop MJ, Müller A. Ultrathin molybdenum polyoxometalate-polyelectrolyte multilayer films. Langmuir 1998;14:3462-5.

[25] Noro S-i, Tsunashima R, Kamiya Y, Uemura K, Kita H, Cronin L, et al. Adsorption and catalytic properties of the inner nanospace of a gigantic ring-shaped polyoxometalate cluster. Angew Chem Int Ed 2009;48:8703-6.

[26] Zhang J, Li W, Wu C, Li B, Zhang J, Wu L. Redox-controlled helical self-assembly of a polyoxometalate complex. Chem Eur J 2013;19:8129-35.

[27] (a) Li B, Zhang J, Wang S, Li W, Wu L. Nematic ion-clustomesogens from surfactantencapsulated polyoxometalate assemblies. Eur J Inorg Chem 2013;2013: 1869-75.

(b) Wu H-L, Zhang Z-M, Li Y-G, Wang E-B. Design and construction of a thermotropic liquid crystal material based on high-nuclear transition-metal cluster-containing polyoxometalates. RSC Adv 2013:4:43806-10.

(c) Jia Y, Zhang J, Zhang Z-M, Li Q-Y, Wang E-B. Metal-centered polyoxometalates encapsulated by surfactant resulting in the thermotropic liquid crystal materials. Inorg Chem Commun 2013;43:5-9.

(d) Li W, Wu L. Hybrid liquid crystals from the self-assembly of surfactantencapsulated polyoxometalate complexes. Chin J Chem 2013:33:15-23.

[28] Li C, Wong W-T. A convenient method for the preparation of mono N-alkylated cyclams and cyclens in high yields. Tetrahedron Lett 2002;43:3217-20.

[29] Lemoigne J, Simon J. New type of surfactant - annelides - characterization of organized metal-ion assemblies obtained by metal complexation at the micelle subsurface. J Phys Chem 1980;84:170-7. 
[30] Neve F, Ghedini M, Demunno G, Levelut AM. Ionic amphiphilic metallomesogens. Chem Mater 1995; 7:688-93.

[31] (a) Bruce DW, Holbrey JD, Tajbakhsh AR, Tiddy GJT. Lyotropoc mesomorphism in surfactant bipyridine complexes of RuII. J Mater Chem 1993;3:905-6.

(b) Holbrey JD, Tiddy GJT, Bruce DW. Amphiphilic terpyridine complexes of ruthenium and rhodium displaying lyotropic mesomorpmism. J Chem Soc Dalton Trans 1993:1769-74

[32] Zhu SS, Swager TM. Lyotropic polymorphosm in oxovanadium complexes. Adv Mater 1995;7:280-3.

[33] Binnemans K, Gorller-Walrand C. Lanthanide-containing liquid crystals and surfactants. Chem Rev 2002;102:2303-45.

[34] Lei H, Liu J, Yan J, Lu S, Fang Y. Luminescent vesicular nanointerface: a highly selective and sensitive "turn-on" sensor for guanosine triphosphate. ACS Appl Mater Interfaces 2014:6:13642-7.

[35] Liu T, Li Y, Yan Y, Li Y, Yu Y, Chen N, et al. Tuning growth of low-dimensional organic nanostructures for efficient optical waveguide applications. J Phys Chem C 2012; 116:14134-8.

[36] Ke H, Ma W, Wang H, Cheng G, Yuan H, Wong W-K, et al. Synthesis, singlet-oxygen photogeneration, two-photon absorption, photo-induced DNA cleavage and cytotoxic properties of an amphiphilic $\beta$-Schiff-base linked $\mathrm{Ru}(\mathrm{II})$ polypyridylporphyrin conjugate. J Lumin 2014;154:356-61.

[37] Iza N, Guerrero-Martinez A, Tardajos G, Ortiz MJ, Palao E, Montoro T, et al. Using inclusion complexes with cyclodextrins to explore the aggregation behavior of a ruthenium metallosurfactant. Langmuir 2015;31:2677-88.

[38] Gohy JF, Lohmeijer BGG, Schubert US. Metallo-supramolecular block copolymer micelles. Macromolecules 2002;35:4560-3.

[39] Kim MH, Woo S-K, Kim KI, Lee TS, Kim CW, Kang JH, et al. Simple methods for tracking stem cells with 64Cu-labeled DOTA-hexadecyl-benzoate. ACS Med Chem Lett 2015;6:528-30.

[40] Polarz S, Bährle C, Landsmann S, Klaiber A. Panoscopic structures by hierarchical cascade self-assembly of inorganic surfactants with magnetic heads containing dysprosium ions. Angew Chem Int Ed 2013;52:13665-70.

[41] Wiener EC, Abadjian MC, Sengar R, Vander Elst L, Van Niekerk C, Grotjahn DB, et al. Bifunctional chelates optimized for molecular MRI. Inorg Chem 2014:53:6554-68.

[42] Li JH, Tang YF, Wang QW, Li XF, Cun LF, Zhang XM, et al. Chiral surfactant-type catalyst for asymmetric reduction of aliphatic ketones in water. J Am Chem Soc 2012; 134:18522-5.

[43] Shen J, Jiang MW, Li YK, Guo CG, Oiu XY, Wang CO. Multi-morphological self-assembled structures of a rod-coil organometallic oligomer. Colloid Polym Sci 2012;290:1193-200.

[44] Gohy JF, Lohmeijer BGG, Alexeev A, Wang XS, Manners I, Winnik MA, et al. Cylindrical micelles from the aqueous self-assembly of an amphiphilic poly(ethylene oxide)b-poly(ferrocenylsilane) (PEO-b-PFS) block copolymer with a metallo-supramolecular linker at the block junction. Chem Eur J 2004;10:4315-23.

[45] Polarz S, Regenspurger R, Hartmann J. Self-assembly of methylzinc-polyethylene glycol amphiphiles and their application to materials synthesis. Angew Chem Int Ed 2007;46:2426-30.

[46] (a) Rosnes MH, Musumeci C, Pradeep CP, Mathieson JS, Long DL, Song YF, et al. Assembly of modular asymmetric organic-inorganic polyoxometalate hybrids into anisotropic nanostructures. J Am Chem Soc 2010;132:15490-2.

(b) Long DL, Tsunashima R, Cronin L. Polyoxometalates: building blocks for functional nanoscale systems. Angew Chem Int Ed 2010;49:1736-58.

(c) Dolbecq A, Dumas E, Mayer CR, Mialane P. Hybrid organic-inorganic polyoxometalate compounds: from structural diversity to applications. Chem Rev 2010;110:6009-48.

(d) Proust A, Matt B, Villanneau R, Guillemot G, Gouzerh P, Izzet G. Functionalization and post-functionalization: a step towards polyoxometalate-based materials. Chem Soc Rev 2010;41:7605-22.

(e) Sanchez C, Soler-Illia GJAA, Ribot F, Lalot T, Mayer CR, Cabuil V. Designed hybrid organic-inorganic nanocomposites from functional nanobuilding blocks. Chem Mater 2010;13:3061-83.

(f) Yin P, Jin L, Li D, Cheng P, Vezenov DV, Bitterlich E, et al. Supramolecular assembly of conjugated polymers containing polyoxometalate terminal side chains in polar and nonpolar solvents. Chem Eur J 2010;18:6754-8.

(g) Song YF, Tsunashima R. Recent advances on polyoxometalate-based molecular and composite materials. Chem Soc Rev 2010;41:7384-402.

(h) Yin P, Li D, Liu T. Solution behaviors and self-assembly of polyoxometalates as models of macroions and amphiphilic polyoxometalate-organic hybrids as novel surfactants. Chem Soc Rev 2010;41:7368-83.

[47] (a) Dolbecq A, Dumas E, Mayer CR, Mialane P. Hybrid organic-inorganic polyoxometalate compounds: from structural diversity to applications. Chem Rev 2010;110:6009-48.

(b) Proust A, Matt B, Villanneau R, Guillemot G, Gouzerh P, Izzet G. Functionalization and post-functionalization: a step towards polyoxometalate-based materials. Chem Soc Rev 2010;41:7605-22.

[48] Zhang J, Song YF, Cronin L, Liu T. Self-assembly of organic-inorganic hybrid amphiphilic surfactants with large polyoxometalates as polar head groups. J Am Chem Soc 2008;130:14408-9.

[49] Zhang J, Song YF, Cronin L, Liu T. Reverse-vesicle formation of organic-inorganic polyoxometalate-containing hybrid surfactants with tunable sizes. Chem Eur J 2010;16:11320-4.

[50] Landsmann S, Lizandara-Pueyo C, Polarz S. A new class of surfactants with multinuclear, inorganic head groups. J Am Chem Soc 2010;132:5315-21.

[51] Landsmann S, Luka M, Polarz S. Bolaform surfactants with polyoxometalate head groups and their assembly into ultra-small monolayer membrane vesicles. Nat Commun 2012;3:1299.
[52] Giner-Casares JJ, Brezesinski G, Mohwald H, Landsmann S, Polarz S. Polyoxometalate surfactants as unique molecules for interfacial self-assembly. J Phys Chem Lett 2012; 3:322-6.

[53] Landsmann S, Wessig M, Schmid M, Colfen H, Polarz S. Smart inorganic surfactants: more than surface tension. Angew Chem Int Ed 2012;51:5995-9.

[54] Baney RH, Itoh M, Sakakibara A, Suzuki T. Silsesquioxanes. Chem Rev 1995;95: 1409-30.

[55] Wang L, Zheng S. Surface morphology and dewettability of self-organized thermosets involving epoxy and POSS-capped poly(ethylene oxide) telechelics. Mater Chem Phys 2012;136:744-54.

[56] (a) Jiang BB, Tao W, Lu X, Liu Y, Jin HB, Pang Y, et al. A POSS-based supramolecular amphiphile and its hierarchical self-assembly behaviors. Macromol Rapid Commun 2012;33:767-72.

(b) Zhang W, Hong L, McGowan PC. A giant capsule from the self-assembly of a penta-telechelic hybrid poly(acrylic acid) based on polyhedral oligomeric silsesquioxane. Macromol Chem Phys 2012;215:900-5.

(c) Zeng K, Zheng S. Nanostructures and surface dewettability of epoxy thermosets containing hepta(3,3,3-trifluoropropyl) polyhedral oligomeric silsesquioxanecapped poly(ethylene oxide). J Phys Chem B 2012;111:13919-28.

(d) Chen L, Zeng B, Xie J, Yu S, Yuan C, Pan Y, et al. A metal-sensitive organicinorganic hybrid surfactant: POSS-capped dipicolinic acid-functionalized poly(ethylene glycol) amphiphile. React Funct Polym 2012;73:1022-9.

[57] Nakanishi T. Supramolecular soft and hard materials based on self-assembly algorithms of alkyl-conjugated fullerenes. Chem Commun 2010;46:3425-36.

[58] (a) Schenning A, George SJ. Self-assembly phases full of fullerenes. Nat Chem 2014; 6:658-9.

(b) Asanuma H, Li HG, Nakanishi T, Mohwald H. Fullerene derivatives that bear aliphatic chains as unusual surfactants: hierarchical self-organization, diverse morphologies, and functions. Chem Eur J 2014;16:9330-8.

[59] (a) Homma T, Harano K, Isobe H, Nakamura E. Preparation and properties of vesicles made of nonpolar/polar/nonpolar fullerene amphiphiles. J Am Chem Soc 2011;133:6364-70.

(b) Hollamby MJ, Karny M, Bomans PHH, Sommerdijk NAJM, Saeki A, Seki S, et al. Directed assembly of optoelectronically active alkyl-pi-conjugated molecules by adding n-alkanes or pi-conjugated species. Nat Chem 2011;6:941 (vol 6, pg $690,2014)$.

[60] Nakanishi T, Ariga K, Michinobu T, Yoshida K, Takahashi H, Teranishi T, et al. Flowershaped supramolecular assemblies: hierarchical organization of a fullerene bearing long aliphatic chains. Small 2007:3:2019-23.

[61] Maierhofer AP, Brettreich M, Burghardt S, Vostrowsky O, Hirsch A, Langridge S, et al. Structure and electrostatic interaction properties of monolayers of amphiphilic molecules derived from C-60-fullerenes: a film balance, neutron-, and infrared reflection study. Langmuir 2000;16:8884-91.

[62] Nakanishi T, Shen Y, Wang J, Li H, Fernandes P, Yoshida K, et al. Superstructures and superhydrophobic property in hierarchical organized architectures of fullerenes bearing long alkyl tails. J Mater Chem 2010;20:1253-60.

[63] Asanuma H, Li H, Nakanishi T, Moehwald H. Fullerene derivatives that bear aliphatic chains as unusual surfactants: hierarchical self-organization, diverse morphologies, and functions. Chem Eur J 2010;16:9330-8.

[64] Matsuo Y. C-60 derivatives having self-assembly capabilities. Fullerenes Nanotubes Carbon Nanostruct 2010;18:338-52.

[65] Michinobu T, Okoshi K, Murakami Y, Shigehara K, Ariga K, Nakanishi T. Structural requirements for producing solvent-free room temperature liquid fullerenes. Langmuir 2013;29:5337-44.

[66] Allen NS, Zeynalov EB, Taylor K, Birkett P. Antioxidant capacity of novel amine derivatives of buckminsterfullerene: determination of inhibition rate constants in a model oxidation system. Polym Degrad Stab 2009;94:1932-40.

[67] (a) Fernandez D, Viterisi A, William Ryan J, Gispert-Guirado F, Vidal S, Filippone $\mathrm{S}$, et al. Small molecule BHJ solar cells based on $\operatorname{DPP}(\mathrm{TBFu})(2)$ and diphenylmethanofullerenes (DPW): linking morphology, transport, recombination and crystallinity. Nanoscale 2014;6:5871-8.

(b) Kaestner C, Ulbricht C, Egbe DAM, Hoppe H. Polymer BHJ solar cell performance tuning by C60 fullerene derivative alkyl side-chain length.J Polym Sci B 2014;50: 1562-6.

[68] Harano K, Minami K, Noiri E, Okamoto K, Nakamura E. Protein-coated nanocapsules via multilevel surface modification. Controlled preparation and microscopic analysis at nanometer resolution. Chem Commun 2013:49:3525-7.

[69] (a) Hilmer AJ, Tvrdy K, Zhang JQ Strano MS. Charge -walled carbon nanotube heterojunctions. J Am Chem Soc 2013;135:11901-10.

(b) Hollamby MJ, Nakanishi T. The power of branched chains: optimising functional molecular materials. J Mater Chem C 2013;1:6178-83.

[70] Aveyard R, Binks BP, Clint JH. Emulsions stabilised solely by colloidal particles. Adv Colloid Interf Sci 2003;100:503-46.

[71] (a) Walther A, Müller AHE. Janus particles. Soft Matter 2008;4:663-8.

(b) Jiang S, Chen Q, Tripathy M, Luijten E, Schweizer KS, Granick S. Janus particle synthesis and assembly. Adv Mater 2008:22:1060-71.

(c) Walther A, Müller AHE. Janus particles: synthesis, self-assembly, physical properties, and applications. Chem Rev 2008;113:5194-261.

[72] (a) Yuwono VM, Burrows ND, Soltis JA, Penn RL. Oriented aggregation: formation and transformation of mesocrystal intermediates revealed. J Am Chem Soc 2010;132:2163.

(b) Song RQ, Colfen H. Mesocrystals-ordered nanoparticle superstructures. Adv Mater 2010;22:1301-30

[73] Fujii S, Sakurai K, Okobira T, Ohta N, Takahara A. Synthesis and characterization of a Calix 4 arene amphiphilie bearing cysteine and uniform Au nanoparticle formation templated by its four cysteine moieties. Langmuir 2013;29:13666-75. 
[74] Yao OF, Yuan X, Yu Y, Yu Y, Xie JP, Lee JY. Introducing amphiphilicity to noble meta nanoclusters via phase-transfer driven Ion-pairing reaction. J Am Chem Soc 2015; 137:2128-36.

[75] Yabu H, Ohshima H, Saito Y. Double-phase-functionalized magnetic Janus polymer microparticles containing $\mathrm{TiO} 2$ and $\mathrm{Fe} 2 \mathrm{O} 3$ nanoparticles encapsulated in mussel-inspired amphiphilic polymers. ACS Appl Mater Interfaces 2014;6: 18122-8.

[76] Wu B, Tang S, Chen M, Zheng N. Amphiphilic modification and asymmetric silica encapsulation of hydrophobic Au-Fe3O4 dumbbell nanoparticles. Chem Commun 2014;50:174-6.
[77] Li PP, Zheng YP, Wu YW, Qu P, Yang RL, Wang N, et al. A nanoscale liquid-like graphene@Fe304 hybrid with excellent amphiphilicity and electronic conductivity. New J Chem 2014;38:5043-51.

[78] Sahoo JK, Tahir MN, Hoshyargar F, Nakhjavan B, Branscheid R, Kolb U, et al. Molecular camouflage: making Use of protecting groups to control the self-assembly of inorganic Janus particles onto metal-chalcogenide nanotubes by Pearson hardness. Angew Chem Int Ed 2011;50:12271-5.

[79] Zhao N, Vickery J, Guerin G, Park JI, Winnik MA, Kumacheva E. Self-assembly of single-tip metal-semiconductor nanorods in selective solvents. Angew Chem Int Ed 2011;50:4606-10. 